\title{
A clinical study of peri operative effectiveness of adjuvant Neostigmine with intrathecal Bupivacaine for lower abdominal surgeries.
}

\author{
Dr. Yoganarasimha $\mathrm{N}^{1}$, Dr. Raghavendra TR ${ }^{2}$, Dr. Radha $\mathrm{MK}^{3}$ \\ ${ }_{1,2,3}$ (Department of Anaesthesiology, Adichunchanagiri Institute of Medical sciences/RGUHS, India)
}

\begin{abstract}
Spinal anaesthesia results in sympathetic blockade, sensory analgesia and motor blockade. It requires a small volume of drug to produce profound and reproducible sensory analgesia and motor blockade; in contrast, epidural anesthesia necessitates the use of a large mass of local anesthetic that produces pharmacologically active systemic blood levels, which may be associated with side effects and complications unknown with spinal anaesthesia. Many lower abdominal surgical procedures require muscle relaxation, and spinal Bupivacaine alone provides only modest motor block. Various drugs have been used along with local anaesthetics for prolongation of spinal analgesia and motor block like opiates, benzodiazepines, clonidine etc. The present study was intended to know whether intrathecal Neostigmine can meet the above mentioned requirements. Methodology: we performed this prospective study on patients posted for lower abdominal surgery belonging to ASA I and age group between 18-60 years after obtaining a written informed consent and

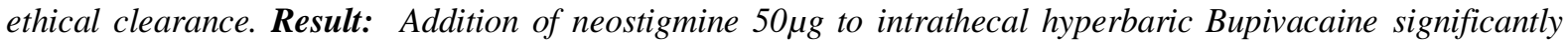
produces prolongation of analgesia than compared to the control group with no serious adverse effects

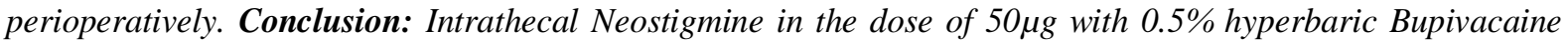
provides an attractive alternative combination to anaesthesiologist armamentarium for managing lower abdominal surgeries.
\end{abstract}

Keywords: Analgesia, Bupivacaine, Hyperbaric, lower abdominal surgery, Neostigmine.

\section{Introduction}

Bupivacaine is the most commonly employed local anaesthetic for sub arachanoid block. Peri operative hemodynamic status and post operative pain relief are important issues with Bupivacaine. Many adjuvants are commonly used to overcome these demerits. So our concern is to choose an adjuvant with Bupivacaine which provides a stable intraoperative condition, prolonging the post operative analgesia with minimal side effects.

Neostigmine is a white crystalline powder which is odorless and readily soluble in water. It is a synthetic quaternary ammonium compound. Neostigmine is an anticholinesterase agent, which inhibits the hydrolysis of acetyl choline by competing with acetylcholine for the attachment to acetyl cholinesterase, as a result acetylcholine accumulates at cholinergic synapses and its effects are prolonged and exaggerated. Spinal Neostigmine apparently activates descending pain inhibitory systems that rely on a spinal cholinergic interneuron, probably exacerbating a cholinergic tonus that is already activated during the post operative period [1] and seems to be extremely efficient for alleviating somatic pain.

\section{Aim Of Study}

To compare the effect of intrathecal Neostigmine in the dose of $50 \mu \mathrm{g}$ with $2.5 \mathrm{ml}$ of $0.5 \%$ hyperbaric Bupivacaine \& $2.5 \mathrm{ml}(12.5 \mathrm{mg})$ of Intrathecal $0.5 \%$ hyperbaric Bupivacaine. With regard to: 1) Sensory characteristics, 2) Motor characteristics, 3) Side effects.

\section{Materials And Methods}

A prospective randomized controlled study was taken up in our institute over a period of 6 months. Inclusion criteria: All patients aged between a) 18-60 years, b) ASA Grade I \& II c) Patients posted for Lower Abdominal Surgeries. Exclusion criteria: a) Patients with local sepsis; b) Patients with bleeding diathesis, c) Patients with raised ICP d) Patients with any co-morbid diseases like IHD, Hypertension, Bronchial asthma, Diabetes Mellitus \& morbidly obese patients.

The study population belonging to the inclusion criteria was divided randomly into two groups (TABLE 1): Group B ( $\mathrm{n}=25)$ served as control, received $2.5 \mathrm{ml}$ of $0.5 \%$ Hyperbaric Bupivacaine along with 0.5 $\mathrm{ml}$ of normal saline. And Group BN $(\mathrm{n}=25)$ received $2.5 \mathrm{ml}$ of $0.5 \%$ hyperbaric Bupivacaine $+50 \mu \mathrm{g}$ of Neostigmine. The study was double blinded, spinal anesthesia was given by the anesthesiologist with the study drug, who was not involved in the patients monitoring. The patients \& the monitoring Anesthesiologist were blinded to the study solutions. Ethical committee clearance \& patients consent were obtained. All the patients 
were premedicated on the night before surgery with tab Ranitidine $150 \mathrm{mg}$ and tab. Alprazolam $0.5 \mathrm{mg}$. On the day of surgery, after securing i.v line with $18 \mathrm{G}$ cannula. Patients were connected to multichannel monitor displaying ECG, SPO2 \& NIBP. All the patients were preloaded with $10 \mathrm{ml} / \mathrm{kg}$ of RL. Under aseptic precautions, lumbar puncture was done using $23 \mathrm{G}$ spinal needle at L2- L3 or L3- L4 space. After confirming the free flow of CSF, the study drugs were injected into the sub-arachanoid space at the rate of $1 \mathrm{ml}$ given in 3 seconds, with the operation table kept flat. Patients were turned supine immediately \& were given supplemental oxygen.

The following parameters were noted after SAB. 1) Time of onset of analgesia $\rightarrow$ defined as time taken from the injection of the drug to onset of analgesia at T-10 level, 2) Maximum level of analgesia achieved. 3) Time taken for achieving maximum level of analgesia, 4) Time taken for onset of motor blockade, 5) Quality of motor blockade assessed by Bromage scale, 6) Total duration of surgery, 7) Intra operative hemodynamic monitoring in the form of HR. SBP\& DBP measured immediately after SAB, $2^{\text {nd }} \min , 5^{\text {th }}$ min, $10^{\text {th }}$ min and every $15 \mathrm{~min}$. till the end of surgery, 8) Total duration of analgesia $\rightarrow$ defined as the time taken from the onset of analgesia to the point where the patient complained of pain in the operated site requiring rescue analgesics (VAS $>5)$.

- Hypotension was defined as reduction of SBP, more than $30 \%$ below the base line value [2] or SBP recording $<90 \mathrm{mmHg}$ [3] and it was treated with increased rate of IV fluids and if needed with Vasopressors.

- Bradycardia was defined as $\mathrm{HR}<60$ beats per minute \& was treated with i.v. atropine.

- Any other side effect associated with the administration of intrathecal Neostigmine was noted.

At the end of the study, the data was complied systematically and was subjected to statistical analysis using student ${ }^{\prime}$ ' test and SPSS version 10.0 for windows. Value of $p<0.05$ was considered significant.

\section{Discussion}

The aim of good post operative analgesia is to produce a long lasting, continuous effective analgesia with minimum side effects. Commonly used local anaesthetics for intrathecal anaesthesia are Lignocaine and Bupivacaine in India. Bupivacaine $0.5 \%$ heavy has more prolonged action compared to Lignocaine but the post operative analgesic duration is limited. Other method of prolonging analgesia is using a continuous epidural analgesia, which is technically more difficult and more costly, which the patients coming to the government hospital may not afford. Hence, an intrathecal additive to these local anaesthetics forms a reliable and reproducible method of prolonged post operative analgesia. This technique being simple and less cumbersome has gained a wide acceptability. Commonly used intrathecal additives to local anaesthetics include Opioids, Clonidine, and Neostigmine.

The groups were comparable with respect to age, sex, weight and ASA physical status. There was no statistically significant difference in the type, duration of surgery $(p>0.05)$ (TABLE 1$)$ and type of surgery (TABLE 2).

Spinal administration of Neostigmine, an acetyl cholinesterase inhibitor, inhibits breakdown of the endogenous neurotransmitter acetylcholine, thereby inducing analgesia [4,5], hence it is an another alternative non opioid additive to local anaesthetics which lacks pruritis, respiratory depression, urinary retention, decreased motility of gut as their side effects. In the present study, we noticed (TABLE 3) that in Group- BN onset time for sensory blockade was earlier compared to Group- B, showing that neostigmine enhances action of spinally administered local anaesthetics. However, there was no clinically significant difference in the maximum level of blockade achieved in both the groups. In Group-BN, we found (Fig. 1) analgesia lasting upto 300 minutes compared to 200 minutes in Group-B. This clearly shows that, intrathecally administered neostigmine, significantly prolongs the duration of analgesia when administered with local anaesthetic agents.

Hemodynamic disturbances following intrathecal local anaesthetics depends upon: a) Segmental site of injection, b) Patient position, c) Rate of injection, d) Temperature of the injected solution, e) Preloading, f) The baricity of local anaesthetics employed.

Intrathecal administration of Neostigmine causes an amplification of action acetylcholine released at preganglionic sympathetic neurons resulting in increase in heart rate and blood pressure [6, 7]. In our study (Fig. 2) intra operative blood pressure was well maintained in the Neostigmine group with minimal magnitude of change occurring as late as $40^{\text {th }}$ min of only $4 \mathrm{mmHg}$ fall of systolic blood pressure compared to $19 \mathrm{mmHg}$ fall at $5^{\text {th }}$ min in Group B concurs with Krukowski et $\mathrm{al}^{6}$ study. However, there was increase in pulse rate of 18 beats/min at $5^{\text {th }}$ min in Neostigmine group, than compared with 10 beats/min increase in Group B at $2^{\text {nd }}$ min this was also observed by JG Klamt [8] with administration of 100 micrograms of Neostigmine intrathecally. This is due to excitatory action of Neostigmine on preganglionic sympathetic neurons are more pronounced after injection directly into intermediolateral cell column than after intrathecal injection [9].

In addition to the potential direct inhibition of motor activity by administration of Neostigmine, it was speculated [10] that increased spinal levels of acetylcholine may augment motor block as a result of axonal 
conduction block from spinal Bupivacaine. Neostigmine enhanced motor block from spinal Bupivacaine may be useful in the clinical setting. Many lower-extremity surgical procedures require muscle relaxation, and spinal Bupivacaine alone provides only modest motor block [11]. In our study (TABLE 4) the mean time for motor onset was significantly faster in Neostigmine group (Group BN=1.96 mins) when compared to Group B=2.44 mins, similarly the mean time taken for maximum motor blockade was clinically and significantly faster in Neostigmine group (Group $\mathrm{BN}=3.32$ mins) than compared to Group $\mathrm{B}=4.64$ mins and mean time taken for regaining complete motor power was prolonged significantly in Neostigmine group (Group BN=193 mins) than Bupivacaine group (Group $B=150$ mins). This concurs with the study result (mean duration of 220 mins) conducted by JG Klamt et al [8].

Nausea, vomiting and urinary incontinence were the most distressing side effects observed in the Neostigmine group using more than 100 micrograms [12]. Cholinergic sites in the brainstem and thoracic and cervical spinal cord may involve in mediation of nausea/vomiting side effect [8]. Roastral spread of Neostigmine to this brainstem site is proposed to be the cause for nausea and vomiting [7, 13]. Hence, by keeping the patients in sitting posture or by diluting the drug with hyperbaric solution prevents the drug to act on supra spinal site to produce this side effect [12]. In the present study (TABLE 5; Fig. 3) perioperatively nausea vomiting were noticed in the both the groups which were statistically in significant $p>0.05$.

TABLE -1: DEMOGRAPHY

\begin{tabular}{|l|l|l|}
\hline & GROUP B & GROUP BN \\
\hline MEAN AGE & 30.8 & 28.72 \\
\hline MEAN WEIGHT & $60.36 \mathrm{Kg}$ & $56.36 \mathrm{Kg}$ \\
\hline MALE:FEMALE RATIO & $18: 07$ & $18: 07$ \\
\hline
\end{tabular}

TABLE-2: SURGICAL PROCEDURE

\begin{tabular}{|l|l|l|}
\hline & GROUP B & GROUP BN \\
\hline $\begin{array}{l}\text { SURGICAL PROCEDURES ( } \\
\text { INGUINAL HERNIA: } \\
\text { APPENDICECTOMY ) }\end{array}$ & $16: 9$ & $15: 10$ \\
\hline
\end{tabular}

TABLE -3: SENSORY CHARATERISTICS

\begin{tabular}{|l|l|l|}
\hline MEAN ONSET TIME & GROUP B & GROUP BN \\
\hline $\begin{array}{l}\text { MEAN Max LEVEL } \\
\text { OBTAINED T5 }\end{array}$ & 1 mins 38secs \\
\hline $\begin{array}{l}\text { MEAN TIME FOR } \\
\text { ACHIEVING MEAN Max } \\
\text { LEVEL }\end{array}$ & 7 mins 24 secs & T4 \\
\hline $\begin{array}{l}\text { MEAN TOTAL DURATION } \\
\text { OF ANALGESIA }\end{array}$ & $207.6 \pm 45$ mins & 6 mins 28secs \\
\hline
\end{tabular}

FIGURE-1: DURATION OF POST OPERATIVE ANALGESIA

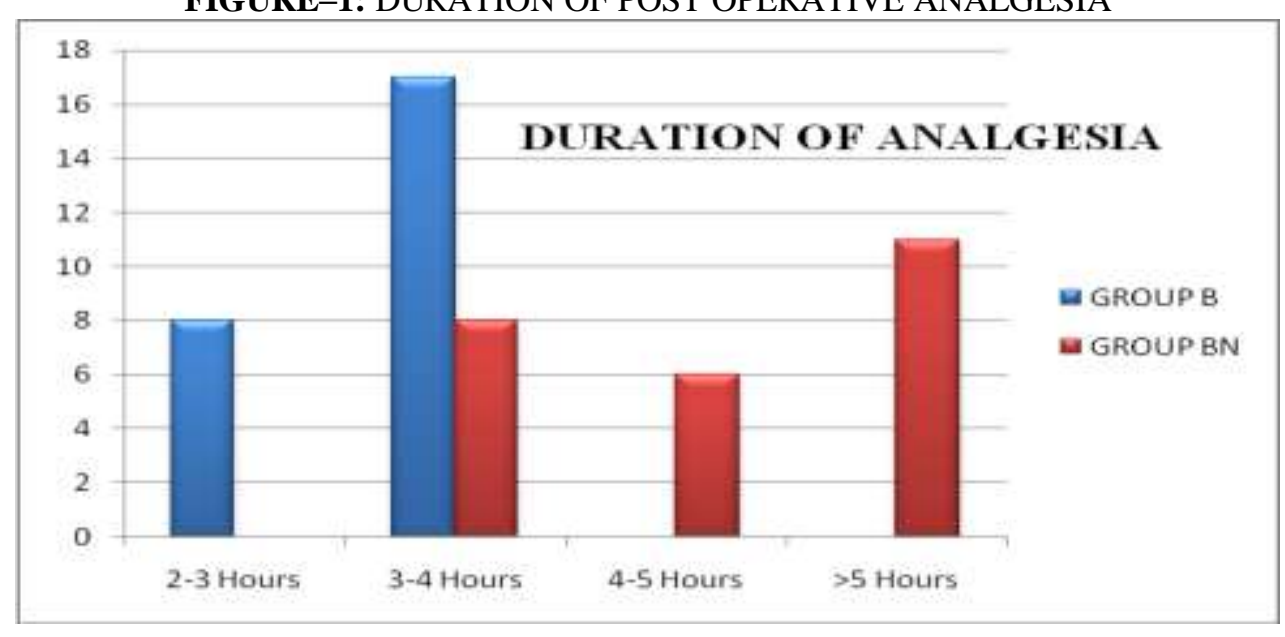


FIGURE -2: HEMODYNAMIC CHANGES - GROUP B \& GROUP BN SYSTOLIC BLOOD PRESSURE

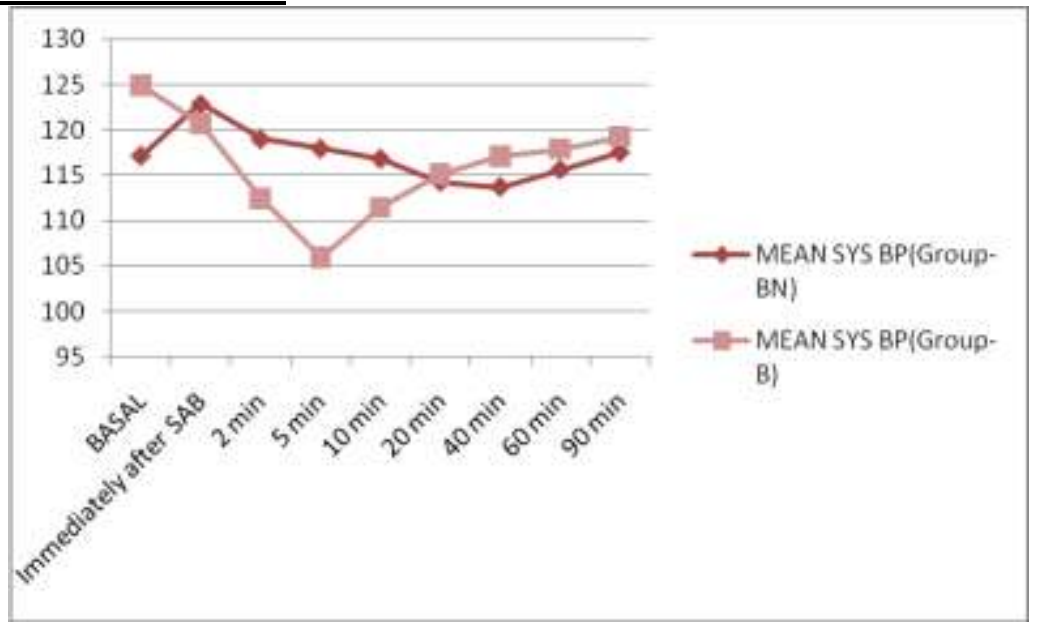

HEART RATE

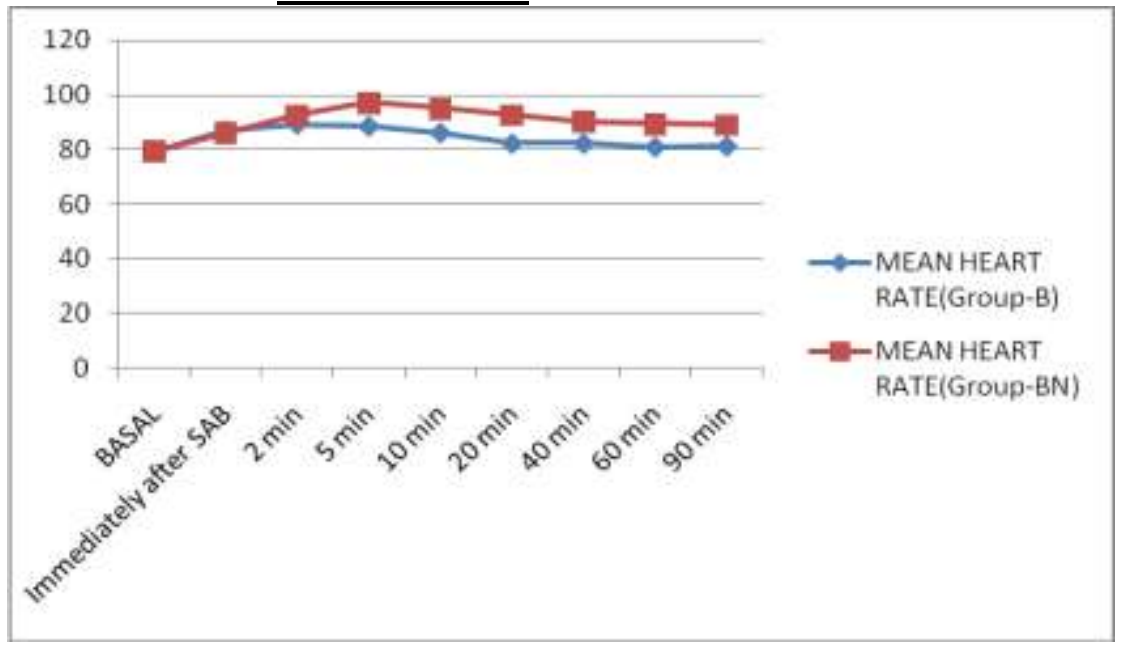

TABLE -4: MOTOR CHARACTERISTICS

\begin{tabular}{|l|l|l|}
\hline & GROUP B & GROUP BN \\
\hline MEAN ONSET TIME & 2mins 44secs & 1mins 56secs \\
\hline $\begin{array}{l}\text { QUALITY O MOTOR } \\
\text { BLOCKADE }\end{array}$ & $\begin{array}{l}\text { Bromge grade III } \rightarrow \text { 85\%, grade } \\
\text { II } \rightarrow 15 \%\end{array}$ & Bromage grade III $\rightarrow 100 \%$ \\
\hline $\begin{array}{l}\text { MEAN TIME REQUIRED TO } \\
\text { ATTAIN MAX MOTOR BLK }\end{array}$ & mins 64secs & 3 mins 32secs \\
\hline $\begin{array}{l}\text { DURATION OF MOTOR } \\
\text { BLOCKADE }\end{array}$ & $150 \pm 38$ mins & $193 \pm 40 \mathrm{mins}$ \\
\hline
\end{tabular}

TABLE -5: PERI OPERATIVE NAUSEA \& VOMITING

\begin{tabular}{|l|l|l|}
\hline \multicolumn{1}{|c|}{ GROUP } & PRESENT & ABSENT \\
\hline GROUP B & 04 & 21 \\
\hline GROUP BN & 06 & 19 \\
\hline
\end{tabular}

FIGURE-3: INCIDENCE OG NAUSEA/VOMITING 


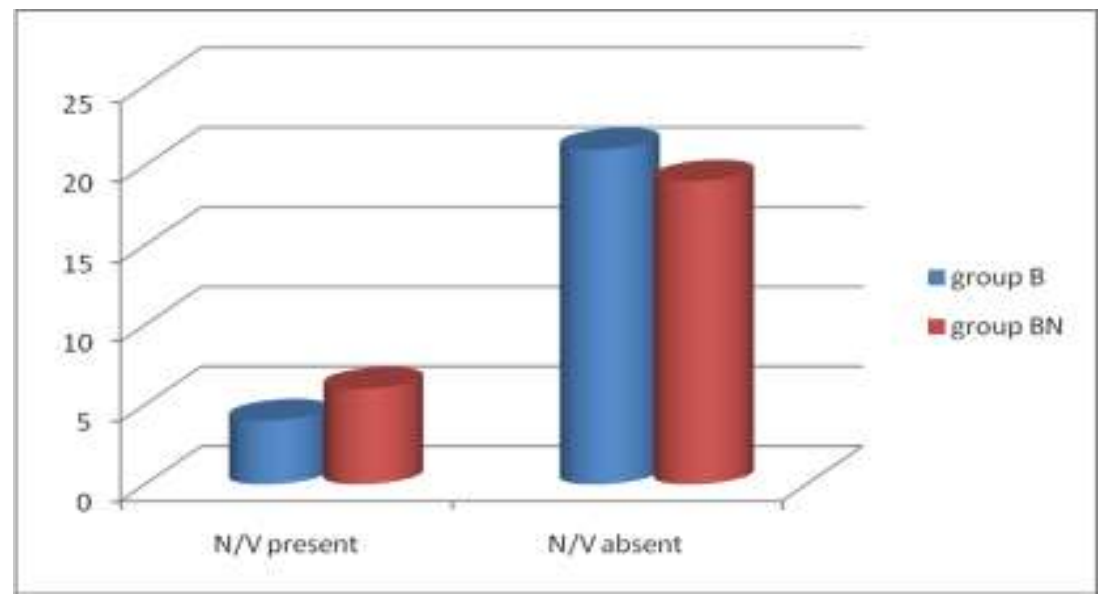

\section{Conclusion}

From the present study, it can be concluded that: A) Intrathecal Neostigmine in the dose of $50 \mu \mathrm{g}$ significantly decreases the onset time of sensory analgesia and motor blockade. B) It significantly prolongs the duration of motor blockade and provides an adequate surgical relaxation intraoperatively C) It provides long

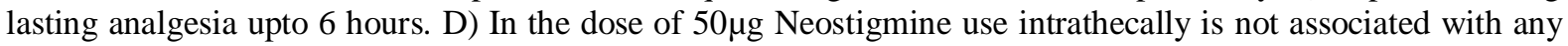
significant hemodynamic disturbance or respiratory depression.

Significant prolongation of analgesia $\&$ adequate motor relaxation without any side effects gives a safe edge in situations where there is unexpected prolongation of surgical procedure.

\section{References}

[1] H Bouaziz, Tong C and James C Eisenach: Post operative analgesia from intrathecal Neostigmine in sheep- Anesthesia and Analgesia; 1995; 80; 1140-1144.

[2] Leland L, Raj Sabar, Alan DK: Chapter 13- Local Anesthetics: P Prithvi Raj Textbook of Regional Anesthesia. 2003 edition; p236.

[3] Bria M. Coates, Monica S. Vavilala, MD, Christopher D. Mack, MS et al The Influence of Definition and Location of Hypotension on Outcome Following Severe Pediatric Traumatic Brain Injury: Crit Care Med. 2005 Nov; 33(11): $2645-2650$.

[4] Liu Spencer S, Hodgson Peter S, Moore James M, Trautman Walter J, Burkhead Daniel L: Dose response effects of spinal Neostigmine added to Bupivacaine spinal anesthesia in volunteers- Anesthesiology 1999; Mar 90(3); 710-717.

[5] Chiari A, Eisenach JC: Spinal anesthesia: Mechanisms, agents, methods, and safety- Reg Anesthesia and Pain Medicine 1998; 23; $357-62$.

[6] James A Krukowski, David D Hood, James C Eisenach, Kathryn A Mallak and R Lamar Parker: Intrathecal Neostigmine for post cesarean section analgesia: Dose response- Anesthesia and Analgesia 1997;84;1269-1275.

[7] Hood David D, Eisenach James C, Tuttle, Robin RN: Phase I safety assessment of intrathecal Neostigmine methylsufate in humans- Anesthesiology 1995; Feb 82(2); 331-343.

[8] JG Klamt, A Slullitel, IV Garcia WA Prado: Post operative analgesic effect of intrathecal Neostigmine and its influence on spinal anaesthesia- Anaesthesia 1997;52;547-551.

[9] Chan-Jong Chung, Ji-Su Kim, Han Suk Park and Young-Jhoon Chin: The efficacy of intrathecal Neostigmine, intrathecal Morphine and their combination for post cesarean section analgesia- Anesthesia and Analgesia 1998; 87; $341-346$.

[10] Liu Spencer S, Hodgson Peter S, Moore James M, Trautman Walter J, Burkhead Daniel L: Dose response effects of spinal Neostigmine added to Bupivacaine spinal anesthesia in volunteers- Anesthesiology 1999; Mar 90(3); 710-717.

[11] Liu SS, Ware PD, Allen HW, Neal JM, and Pollock JE: Dose response characteristics of spinal Bupivacaine in volunteers: Clinical implications for ambulatory anesthesia- Anesthesiology 1996; Oct 85(4); 729-736.

[12] JG Klamt, LV Garcia and WA Parado: Analgesia and adverse effects of a low dose of intrathecally administered hyperbaric Neostigmine alone or combined with Morphine in patients submitted to spinal anaesthesia: pilot study- Anaesthesia 1999; 54; 2731.

[13] James C Eisenach, David D Hood, and Regina Curry: Phase I human safety assessment of intrathecal Neostigmine containing methyl and prophylparaben- Anaesthesia \& Analgesia 1997; 85; 842-846. 